\title{
Problems of Ferrite Content Determination
}

\author{
Bálint Bögre ${ }^{1 *}$, István Mészáros \\ ${ }^{1}$ Department of Materials Science and Engineering, Faculty of Mechanical Engineering, Budapest University of Technology and \\ Economics, H-1111 Budapest, Bertalan Lajos u. 7., Hungary \\ *Corresponding author, e-mail: bbalint1113@gmail.com
}

Received: 29 September 2019, Accepted: 25 March 2020, Published online: 29 April 2020

\begin{abstract}
In this work five different methods - AC magnetometer, DC magnetometer, Feritscope, EBSD and X-ray diffraction - were compared with each other. These methods were used to determine the $\delta$-ferrite content of samples. The limits, disadvantages and advantages of the applied methods were analyzed. The tested material was 2507 type super-duplex stainless steel. The samples were cold rolled and heat treated to modify their ferrite content.
\end{abstract}

Keywords

ferrite content, alternating current magnetometer, direct current magnetometer, Feritscope, EBSD, X-ray diffraction

\section{Introduction}

The large development of industry helped the spread of nondestructive testing (NDT) and evaluation because of its benefic properties. The aim of the fast and widely useable NDT can be defect (cracks, voids etc.) detection or study of the material properties without damaging the sample. Several NDT methods are used in industrial practice from which those methods are investigated in this paper which are suitable to determine ferrite content. Alternating Current (AC) magnetometer, Direct Current (DC) magnetometer, Feritscope, EBSD and X-ray diffraction were applied to measure the $\delta$-ferrite content of cold rolled and heat treated Super-Duplex Stainless Steel (SDSS) samples [1-4].

SDSS is a particular category of stainless steels characterized by a double-phase microstructure with about equal proportions of austenite and ferrite phases. The combination of properties, including high strength and excellent resistance to corrosion and stress corrosion cracking in chloride ion containing environments make SDSS very attractive for many applications. The mixed ferrite/austenite micro-structure leads to different advantages if compared with austenitic and ferritic stainless steels. In fact, SDSS shows higher toughness than most ferritic grades, improved stress corrosion cracking resistance than most austenitic grades, and higher strength than most grades of either type.

Unfortunately, there are several disadvantages due to the metastable structure of duplex stainless steels.
Undesirable secondary phases can form during improper heat treatments in the critical temperature range of 300$1000{ }^{\circ} \mathrm{C}$. The precipitation is mainly associated with the ferrite phase, due to its higher $\mathrm{Cr}$ and Mo content, lower solubility of $\mathrm{N}$ and $\mathrm{C}$ and higher diffusion rates within the body-centered cubic lattice than in austenitic phase. The decomposition of ferrite leads to the formation of many different secondary phases, like $\sigma$-phase, $\chi$-phase, carbides of $\mathrm{M}_{7} \mathrm{C}_{3}$ and $\mathrm{M}_{23} \mathrm{C}_{6}$, nitrides $\mathrm{Cr}_{2} \mathrm{~N}$ and $\mathrm{CrN}$, secondary austenite, $R$-phase, $\pi$-phase. The appearance of these chemical compound phases can cause the dramatical decrease of ductility. The most important phase transformation process in duplex stainless steel is the eutectic decomposition of $\delta$-ferrite which means the transformation of the $\delta$-ferrite into sigma phase and secondary austenite due to heat treatment $\left(\delta \rightarrow \sigma+\gamma_{2}\right)$ [5-11].

Determination of ferrite content is essential in heat treated or welded duplex stainless steel structures. SDSS contains about 50-50 \% ferrite and austenite which rate ensures the favorable properties of the material. If the well-adjusted ferrite content changes these benefic properties can disappear. For example, some percentage decrease of the ferrite content can significantly decrease the corrosion resistance and impact energy of SDSS.

The aim of this study was to compare the capabilities of five different methods which are suitable for ferrite content determination. 


\section{Tested samples}

For studying the capabilities of the before mentioned methods the 2507 grade SDSS was chosen as a model material. This SDSS contains about $25 \%$ chromium and $7 \%$ nickel as main alloying elements. Table 1 shows the complete nominal chemical composition. The most important mechanical properties are summarized in Table 2.

From the original sheet material 35 uniform samples were cut with the size of $15 \times 10 \times 100 \mathrm{~mm}$. Samples were cold rolled at room temperature with six different reduction rates. The rolling reduction was calculated by the commonly used way Eq. (1):

$\varepsilon=\left(h_{0}-h\right) / h_{0} * 100$,

where $h$ is the height of the rolled sample, $h_{0}$ is the height of the original sample $(10 \mathrm{~mm})$. The extents of the cold rolling reduction were $0,10.3,22.3,31.3,41.6$, 50.6, $61.9 \%$, five samples were made in each deformation rates. The rolled samples were heat treated at $700{ }^{\circ} \mathrm{C}, 750{ }^{\circ} \mathrm{C}$, $800{ }^{\circ} \mathrm{C}, 850{ }^{\circ} \mathrm{C}$ temperatures for 30 minutes and cooled in normal air. An additional sample series stayed without heat treatment (formally heat treated at $20{ }^{\circ} \mathrm{C}$ room temperature). At the end of the preparation process all samples were milled for the same geometry $(3.4 \times 10 \times 100 \mathrm{~mm})$ which was suitable for the applied AC magnetometer and Feritscope devices. The DC magnetometer requires bulk specimens, so the milled samples were cut into more pieces and fixed into a rectangular cuboid $(10 \times 10 \times 10.2 \mathrm{~mm})$. The EBSD and X-ray diffraction measurements were used on the either piece of the cut samples.

\section{Applied methods}

Fig. 1 shows the block scheme of the AC magnetometer [12]. This method is suitable to measure the hysteresis and normal magnetization curves of the specimen from which among others the maximal polarization, remnant induction, coercive field and initial permeability

Table 1 Chemical composition of the 2507 type SDSS (\%)

\begin{tabular}{lccccc}
\hline $\mathrm{C}$ & $\mathrm{Mn}$ & $\mathrm{P}$ & $\mathrm{S}$ & $\mathrm{Si}$ & $\mathrm{Cu}$ \\
\hline 0.02 & 0.8 & 0.02 & 0.0004 & 0.31 & 0.17 \\
\hline $\mathrm{Ni}$ & $\mathrm{Cr}$ & $\mathrm{Mo}$ & $\mathrm{Nb}$ & $\mathrm{Ti}$ & $\mathrm{N}$ \\
6.5 & 24.7 & 3.7 & 0.008 & 0.005 & 0.26 \\
\hline
\end{tabular}

Table 2 The most important mechanical properties of the 2507 type SDSS

\begin{tabular}{lcc}
\hline$R_{p 0,2}(\mathrm{MPa})$ & $R_{m}(\mathrm{MPa})$ & $A(\%)$ \\
\hline 634 & 829 & 30 \\
\hline
\end{tabular}

can be determined. The yoke contains two symmetrical U-shaped laminated FeSi cores which closes the magnetic circuit. A digital function generator and a power amplifier produce sinusoidal excitation current at a frequency of $5 \mathrm{~Hz}$. The driving coil and the pick-up coil are around the middle part of the sample. A 16 bit input-output data acquisition card accomplish the measurements. The maximum excitation field strength was 12800 A/m. 200 minor hysteresis loops were measured in case of each specimens. The normal magnetization curves which are determined from the peak points of the minor hysteresis loops gave the maximal polarization. As it is well known the value of maximal polarization is directly proportional to the ferrite content of the specimen [13]. The maximal excitation field of the AC magnetometer was about $128 \mathrm{~A} / \mathrm{cm}$ which therefore it was not able to excite the samples into saturation.

Fig. 2 represents the construction of the so called StableinSteinitz DC magnetometer [14, 15]. The symmetrical yoke consists of two U-shaped parts and a small cross-section middle bridge. The set-up contains four excitation coils, two Hall-sensors and two uniform sized air gaps, namely the measuring and the reference air gaps. If the measuring

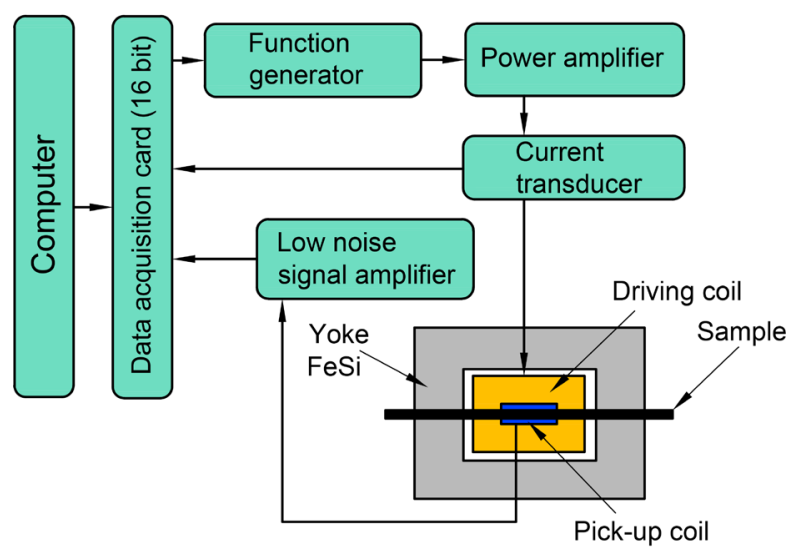

Fig. 1 Block scheme of the AC magnetometer [12]

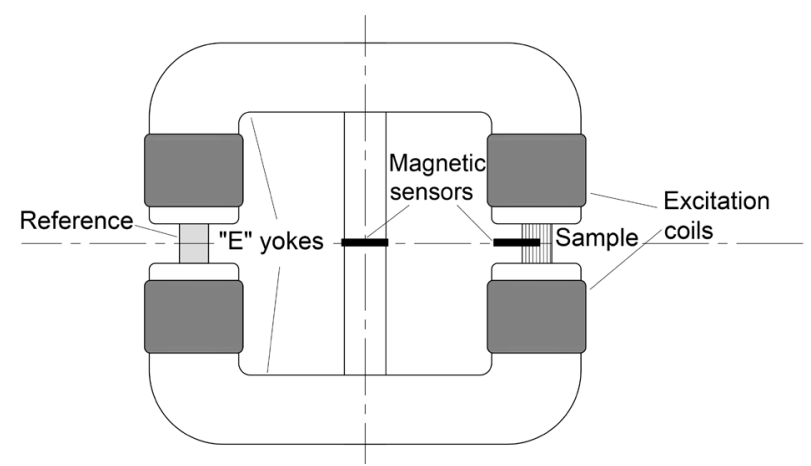

Fig. 2 The construction of the Stablein-Steinitz DC magnetometer $[14,15]$ 
air gap does not contain sample the arrangement is magnetically symmetrical consequently there is no flux through the middle bridge. If the sample is fixed into the measuring air gap the symmetry is broken therefore some part of the magnetic flux closes through the middle bridge. The magnetic field which is measured by a Hall-sensor in the middle bridge is directly proportional to the magnetization of the sample. The Stablein-Steinitz DC magnetometer is capable to excite the bulk steel samples into magnetic saturation which makes it one of the most precise way of the ferrite content measurement. The maximum excitation field strength was about $2700 \mathrm{~A} / \mathrm{cm}$. This set-up is not portable it is only for laboratory use because of its extensive size.

Samples were also measured by a Fischer FERITSCOPE FMP30 type Feritscope equipment. It contains a measuring device, a probe and an etalon series for calibration. According to its user manual it is suitable to measure the ferrite content in austenitic and duplex steels and it can determine the ferrite content in a range of 0.1 to 110 Ferrite Number (FN) or 0.1 to $80 \%$. Fig. 3 shows the schematic set-up of the Feritscope [16]. This user friendly portable measuring device especially useful for quick determination of ferrite content. Because of its physical limitations its excitation level is low. The Feritscope device derives the ferrite content from the initial permeability of the sample.

Ferrite content of some samples were determined by EBSD measurement in a Philips XL30 ESEM FEGtype scanning electron microscope. The EBSD is a technique which can give information about grain size and distribution, texture, boundary characteristics and phase identification. Fig. 4 shows the set-up of an EBSD measurement system. The EBSD is based on the back scattered electron diffraction. The primer electrons scatter inelastic in the sample which is fixed in front of the primer electron

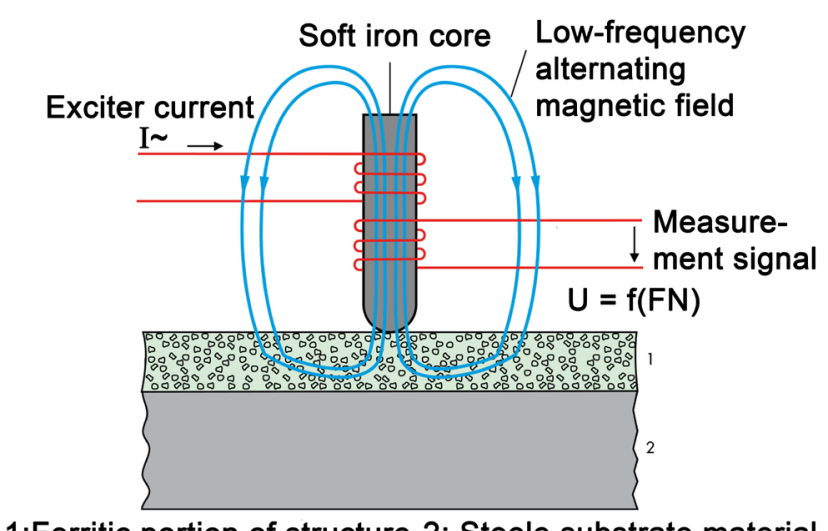

1:Ferritic portion of structure 2: Steele substrate material

Fig. 3 The set-up of the Fischer FERITSCOPE FMP30 [16]



Fig. 4 Set up of an EBSD measurement system

beam. These electrons scatter again elastic on some crystallographic plane according to Bragg's law. During this elastic diffraction the electrons scatter along a cone superficies. In the intersection plane of this cone superficies and a phosphor screen the so called Kikuchi-pattern can appear. The crystallographic structure and the orientation of the investigated point can determine analyzing the lines of the Kikuchi-pattern. The lateral resolution of the EBSD technology is about $0.5 \mu \mathrm{m}$ and it requires careful sample preparation during the polishing and cleaning procedure [17-18].

$\mathrm{X}$-ray diffraction was used to measure the ferrite content of some sample. Fig. 5 represents the block diagram of the X-ray diffraction. This method can determine the atomic and molecular structure of a crystal. The crystalline material causes the scatter of the incident beam into many directions. Using the angles and intensities of the diffracted beams the positions of the atoms in the crystal, the chemical composition of the material, phase ratio, crystallographic disorder and various other information can be calculated [19].

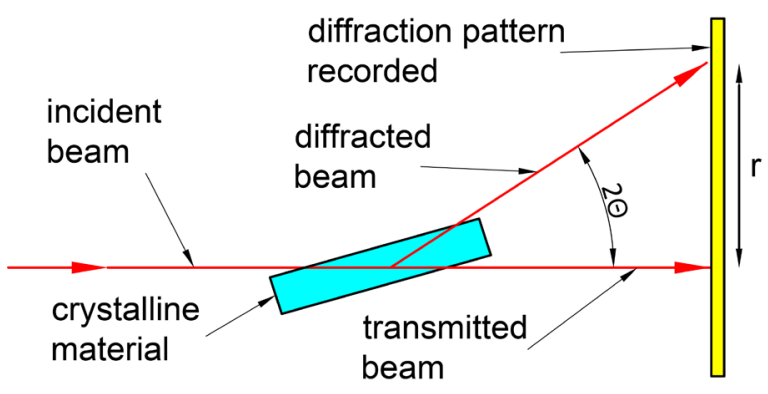

Fig. 5 Block diagram of the X-ray diffraction 


\section{Experimental work}

\subsection{AC magnetometer measurement}

AC magnetometer measurement was suitable to determine the normal magnetization curves of the specimens up to about $12800 \mathrm{~A} / \mathrm{m}$ excitation field. Fig. 6 shows the normal magnetization curves of the $0 \%, 31.3 \%$ and $61.9 \%$ deformed samples.

It can be seen the normal magnetization curves cannot reach the saturation level because of the limited exciting magnetic field strength. As it was mentioned before the ferrite content can be accurately determined from the
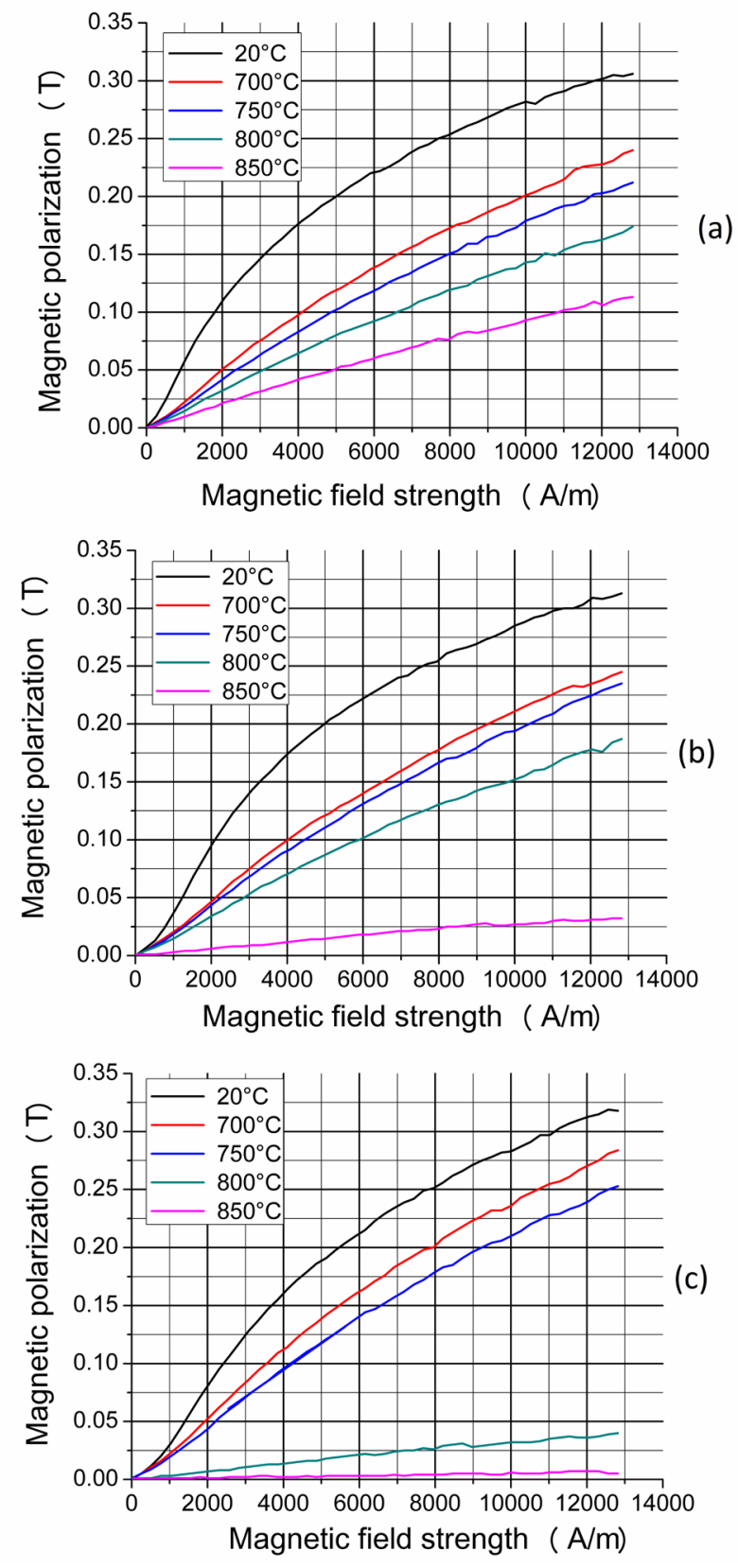

Fig. 6 Normal magnetization curves: (a) $\varepsilon=0 \%$ (b) $\varepsilon=31.3 \%$ (c) $\varepsilon=61.9 \%$ saturation polarization. As it can be seen the maximum polarization values in our AC measurement are lower than the real saturation level.

\subsection{DC magnetometer measurement}

Magnetic hysteresis loops of the samples were recorded by DC magnetometer measurement. Fig. 7 shows the magnetic hysteresis loop of the initial sample (undeformed, without heat treatment) as an illustration.

In this measurement the highest excitation field was about $270000 \mathrm{~A} / \mathrm{m}$ which is enough to saturate completely the tested sample. The ferrite content was calculated from the maximal value of polarization which was considered as the saturation value.

\subsection{Feritscope}

The measurement with Feritscope is a user-friendly method which does not require calculation. The Feritscope device indicates immediately the ferrite content if the probe is put on the surface of the sample. Calibration is necessary with an etalon series before the measurement.

\subsection{EBSD}

The used SEM has a point-source cathode of tungsten, which has a surface layer of zirconia $\left(\mathrm{ZrO}_{2}\right)$. The acceleration voltage is continuously variable from 0.2 till $30 \mathrm{kV}$ and the size of the specimen stage is $50 \mathrm{~mm} \times 50 \mathrm{~mm} \times 50 \mathrm{~mm}$. Table 3 shows the samples which were measured by EBSD.

The samples were inset into resin and were grinding in 8 steps from $\mathrm{P} 60$ to $\mathrm{P} 4000 \mathrm{SiC}$ grinding paper. Colloidal silica was used during the polishing and the polishing time was about 30 minutes by each sample. After the polishing the samples were cut down from the resin and were fixed in the specimen stage. Fig. 8 shows the EBSD phase maps

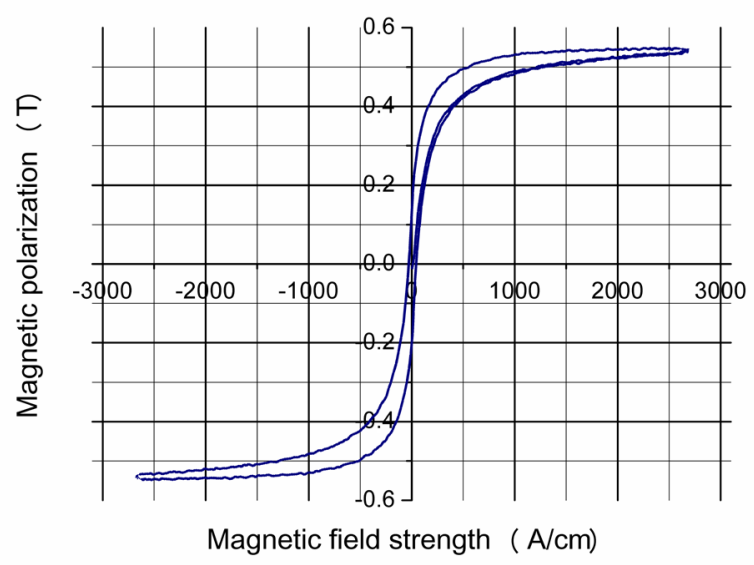

Fig. 7 Magnetic hysteresis loop of the sample in its initial state 
Table 3 Measured samples by EBSD

\begin{tabular}{lc}
\hline Rolling reduction $(\%)$ & Heat treatment temperature $\left({ }^{\circ} \mathrm{C}\right)$ \\
\hline undeformed & without heat treatment \\
22.3 & \\
31.3 & $850{ }^{\circ} \mathrm{C}$ \\
41.6 & \\
61.9 & \\
\hline
\end{tabular}

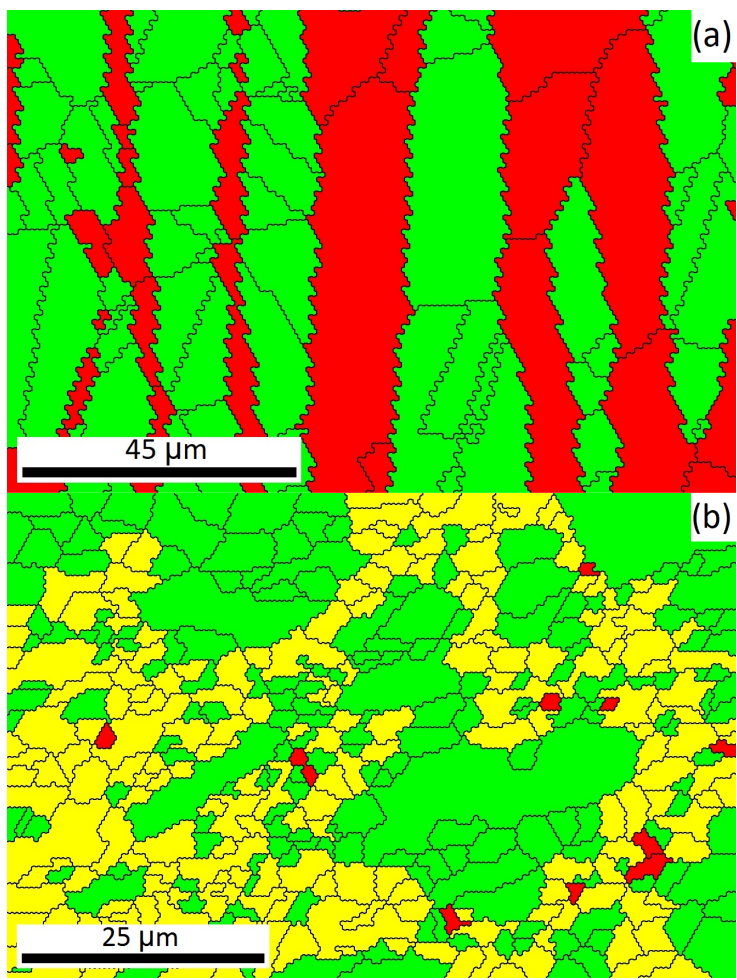

Fig. 8 EBSD phase maps: (a) $\varepsilon=0 \%$ raw material without heat treatment (b) $\varepsilon=61.9 \%$ deformed and heat treated at $850{ }^{\circ} \mathrm{C}$ samples

of the $\varepsilon=0 \%$ raw material without heat treatment (a) and the $\varepsilon=61.9 \%$ deformed and heat treated at $850{ }^{\circ} \mathrm{C}$ sample. The color markings are the following: red $-\delta$-ferrite, green - austenite, yellow $-\sigma$-phase.

\subsection{X-ray diffraction}

The X-ray diffraction measurements were carried out in the Institute of Physical Metallurgy, Metalforming and Nanotechnology at the University of Miskolc. The ferrite contents were measured by two different X-ray diffraction instruments. A D8 Advanced diffractometer with cobalt $\mathrm{X}$-ray was used to the first X-ray diffraction measurement. The qualitative phase analysis was used by Bruker EVA software and PDF 2 database, the quantitative phase analysis was evaluated by APX63 software. Another Bruker D8 Advanced diffractometer with copper X-ray was applied to the second X-ray diffraction measurement. In this case the ferrite contents were determined by Rietveld fitting with Bruker Topas software. Table 4 shows the measured samples and the applied X-ray diffraction instruments.

Fig. 9 demonstrates the diffractogram of the raw material and the $\varepsilon=61.9 \%$ deformed on $T=850{ }^{\circ} \mathrm{C}$ heat treated sample.

\subsection{Comparison of the measuring results}

The results of the $\mathrm{AC}$ and $\mathrm{DC}$ magnetometer measurements were compared on the Fig. 10. It can be seen the ferrite contents of the $\mathrm{AC}$ magnetometer measurement were lower than the results of the DC magnetometer measurement by all three rolling reductions. The maximal excitation field of the AC magnetometer was not able to excite the samples into saturation.

Therefore, a model-based extrapolation method was used to calculate the values of saturation polarization. The base of the applied extrapolation method was the so called multiphase hyperbolic model which suggests the following Eq. (2) formula to the extrapolation:

Table 4 Measured samples by X-ray diffraction

\begin{tabular}{lccc}
\hline & & \multicolumn{2}{c}{ X-ray diffraction instrument } \\
$\begin{array}{l}\text { Rolling } \\
\text { reduction } \\
(\%)\end{array}$ & $\begin{array}{c}\text { Heat } \\
\text { treatment } \\
\text { temperature } \\
\left({ }^{\circ} \mathrm{C}\right)\end{array}$ & $\begin{array}{c}\text { Bruker D8 } \\
\text { Advanced } \\
\text { diffractometer } \\
\text { with cobalt X-ray }\end{array}$ & $\begin{array}{c}\text { Bruker D8 } \\
\text { Advanced } \\
\text { diffractometer } \\
\text { with copper X-ray }\end{array}$ \\
\hline & $\begin{array}{c}\text { without heat } \\
\text { treatment }\end{array}$ & $\times$ & $\times$ \\
undeformed & $750{ }^{\circ} \mathrm{C}$ & $\times$ & - \\
& $850^{\circ} \mathrm{C}$ & $\times$ & - \\
31.3 & $850{ }^{\circ} \mathrm{C}$ & $\times$ & - \\
61.9 & $750{ }^{\circ} \mathrm{C}$ & $\times$ & $\times$ \\
\hline
\end{tabular}

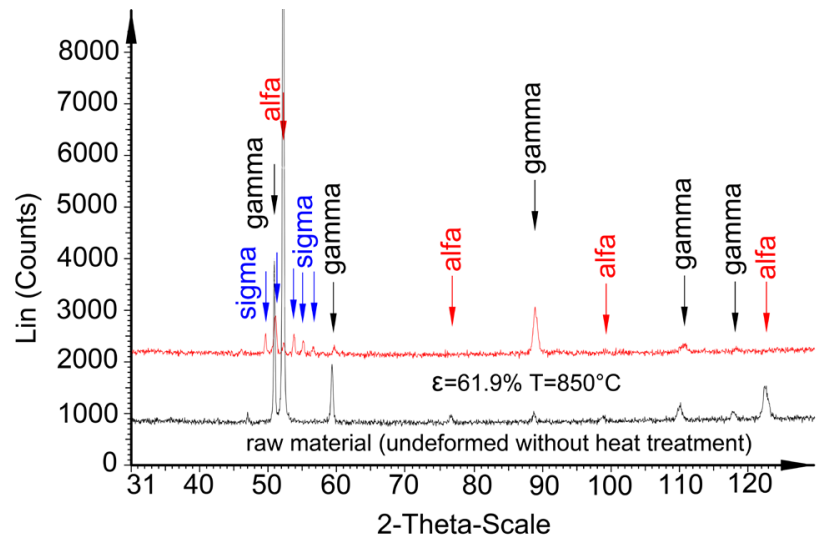

Fig. 9 Diffractogram (raw material and the $\varepsilon=61.9 \%$ deformed on $T=850{ }^{\circ} \mathrm{C}$ heat treated sample) 

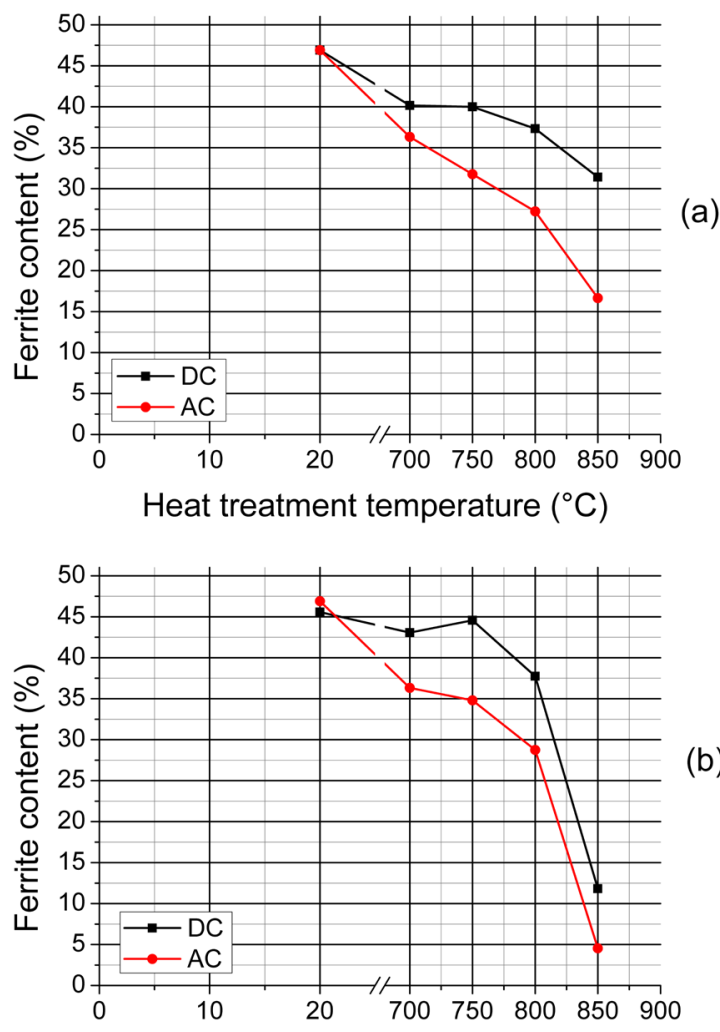

Heat treatment temperature $\left({ }^{\circ} \mathrm{C}\right)$

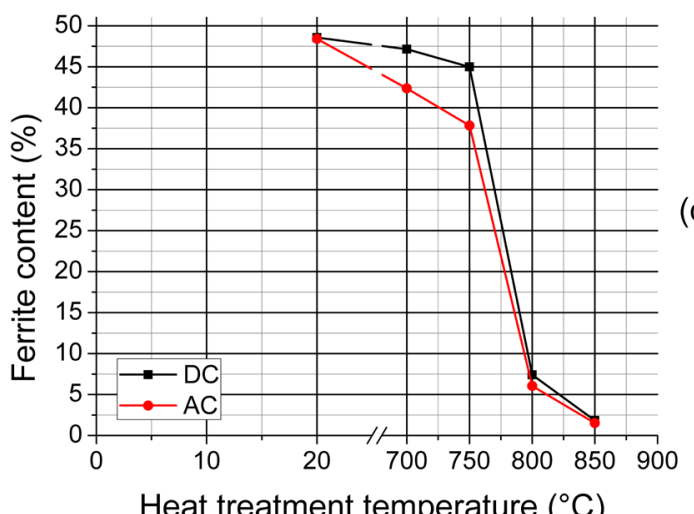

Fig. 10 Ferrite content comparison of the $\mathrm{AC}$ and the $\mathrm{DC}$ magnetometer measurement: (a) $\varepsilon=0 \%$ (b) $\varepsilon=31.3 \%$ (c) $\varepsilon=61.9 \%$

$$
\begin{aligned}
& \frac{M(H)}{M_{0}}=\frac{\tanh \left[N_{i 1}\left(H+\alpha_{1}\right)\right]+\tanh \left[N_{i 1}\left(H-\alpha_{1}\right)\right]}{2(1+\pi+\Phi)} \\
& +\pi \frac{\tanh \left[N_{i 2}\left(H+\alpha_{2}\right)\right]+\pi \tanh \left[N_{i 2}\left(H-\alpha_{2}\right)\right]}{2(1+\pi+\Phi)} \\
& +\Phi \frac{\tanh \left(N_{r} H\right)}{1+\pi+\Phi},
\end{aligned}
$$

where $N_{i 1}, N_{i 2}, N_{r}, \pi, \Phi, \alpha_{1}, \alpha_{2}$ are the fitting parameters of the model. The nonlinear regression was done by using the OriginPro 8 program. The details of the multiphase hyperbolic model are described in our previous paper [20, 21].
Fig. 11 compares the values of the measured ferrite contents by the AC magnetometer, AC magnetometer after the extrapolation and the DC magnetometer. The plotted results belong to three samples of $0 \%, 31.3 \%$ and $61.9 \%$ rolling reduction.

It can be seen the extrapolated results obtained by $\mathrm{AC}$ magnetometer are in good accordance with the results of the DC magnetometer measurement in case of each deformation rates.
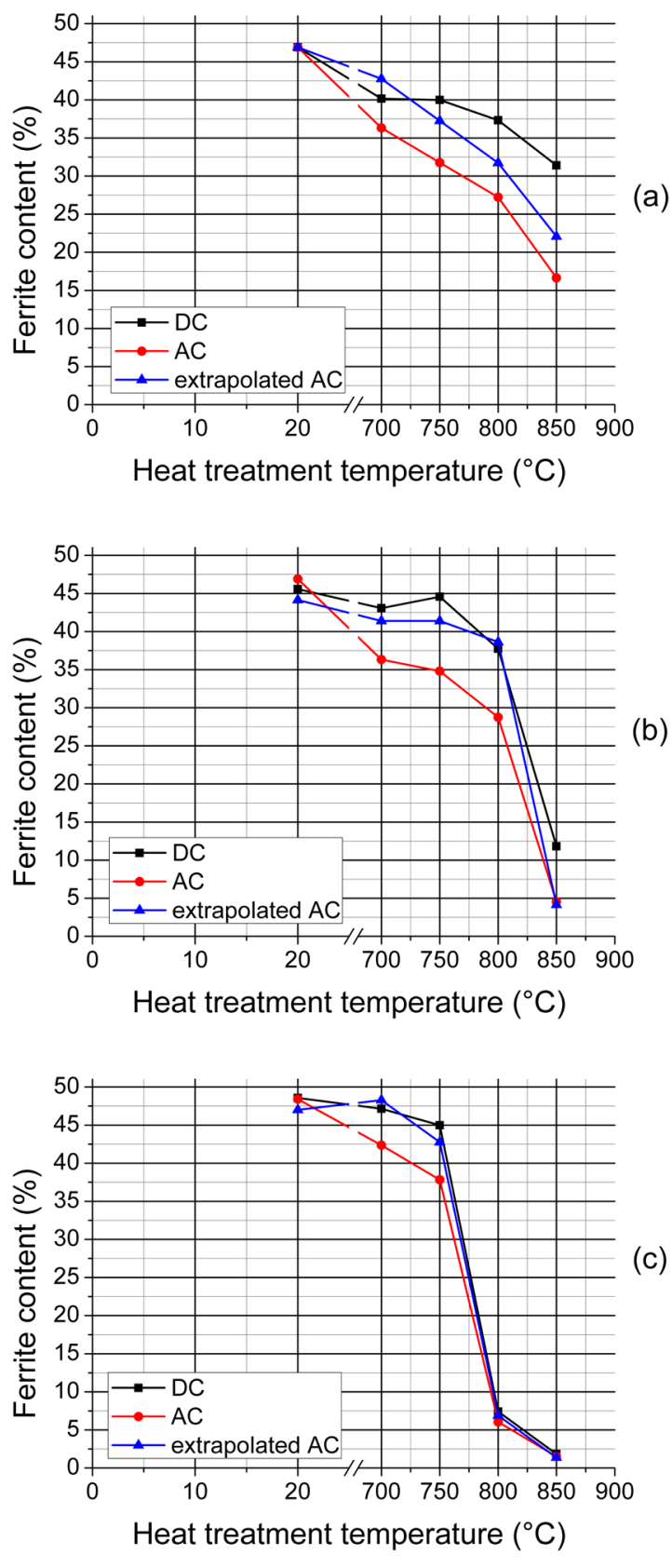

Fig. 11 Ferrite content comparison of the AC magnetometer, the AC magnetometer after the extrapolation and the DC magnetometer:

(a) $\varepsilon=0 \%$ (b) $\varepsilon=31.3 \%$ (c) $\varepsilon=61.9 \%$ 
It is considered the DC magnetometer is the precise and physically correct method to the ferrite content determination due to it can excite the samples into saturation. The DC magnetometer requires bulk samples therefore the cutting is generally essential.

The determination of the ferrite content is much practical using AC magnetometer because of its smaller and easier transportable size and it does not require bulk samples. However the AC magnetometer has lower accuracy than the DC magnetometer. The extrapolation using the Eq. (2) formula can adapt the AC magnetometer such ferrite content measuring method which can well approach the accuracy of the DC magnetometer.

Fig. 12 shows the ferrite content of the non- heat treated sample series in function of the rolling reduction in case of the DC magnetometer and the Feritscope. The ferrite content is nearly constant at DC magnetometer measurement. Surprisingly, the ferrite values of the Feritscope decreases strongly in function of the rolling reduction. If the extent of the cold rolling is strong the ferrite content decreasing can be about $6-8 \%$. It is known that the austenite is a stable phase in the 2507 type SDSS so the cold rolling cannot decrease its ferrite content.

Fig. 13 shows the explanation of this virtual ferrite content reduction. The cold rolling increases the coercive field because the dislocations induced by plastic deformation make the domain walls movement difficult. If the domain walls are prohibited in their motion the value of the coercive field increases.

Therefore, the normal magnetization curve of the deformed sample runs under the curve which belongs to the undeformed specimen. It is supposed the Feritscope derives the ferrite content from the initial permeability of the sample.

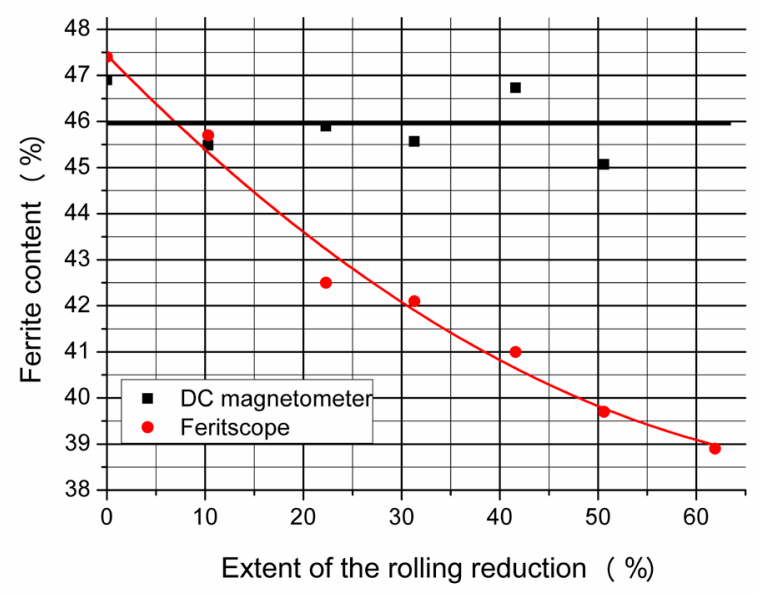

Fig. 12 Ferrite content of the non-heat treated sample series in function of the rolling reduction

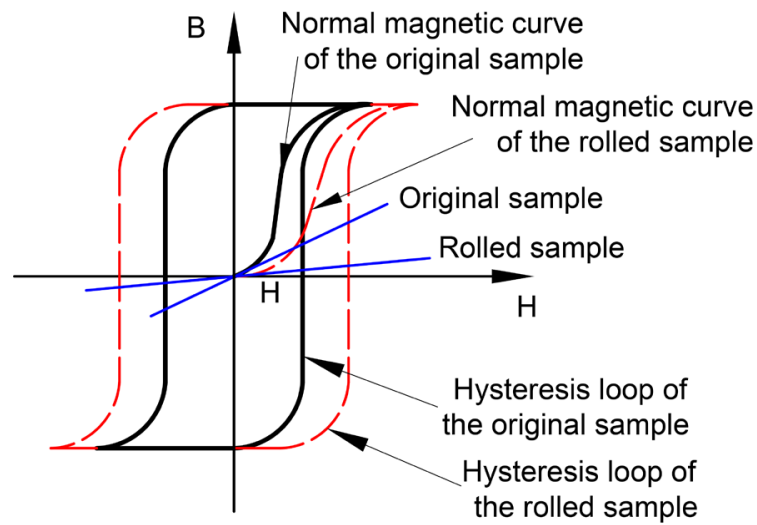

Fig. 13 The effect of the previous cold rolling for the ferrite measurement in case of the Feritscope

Nevertheless, as it can be seen in Fig. 13 the value of the initial permeability strongly influenced by plastic deformation extent. Namely, it will be lower at the deformed sample compared to the undeformed specimen. Consequently, if the ferrite content of a deformed sample is derived from initial permeability it will be lower than its real value.

Fig. 14 compares the ferrite content results of the DC magnetometer, the EBSD, the first and second X-ray diffraction measurement. The measured points are plotted in function of the results of the DC magnetometer. It can be seen the ferrite contents of the EBSD and the second X-ray diffraction measurement are quite close to the results of the DC magnetometer but are slightly lower. The ferrite content differences are between 0.5-5.9 percentage point. The results of the first X-ray diffraction measurement show the highest ferrite content differences from the DC magnetometer which can be more than 11 percentage point. In addition, the first X-ray diffraction measurement determined unrealistic high $\sigma$ phase content by the $\varepsilon=31.3 \%$ and $\varepsilon=61.9 \%$ rolled and heat treated at $850{ }^{\circ} \mathrm{C}$ samples which clarification requires further investigation.

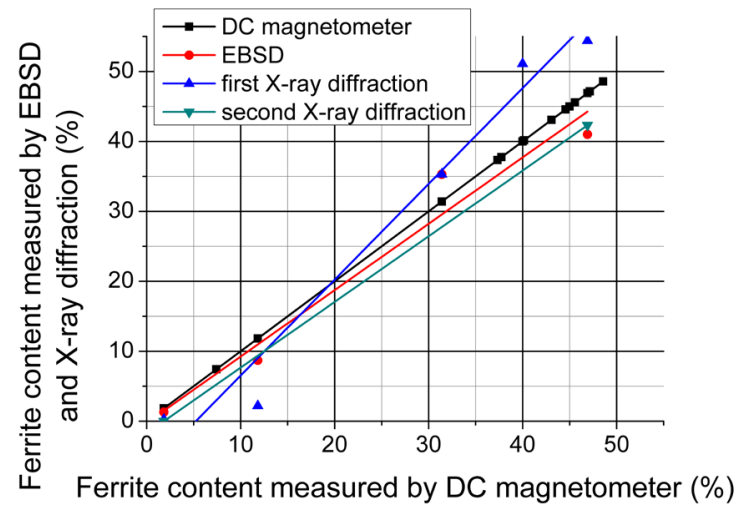

Fig. 14 Ferrite content comparison of the DC magnetometer, the EBSD and the X-ray diffraction measurement 


\section{Summary and conclusions}

Five methods - AC magnetometer, DC magnetometer, Feritscope, EBSD and X-ray diffraction measurement - were compared with each other which were suitable to determine $\delta$-ferrite content of cold rolled and heat treated SDSS samples.

The DC magnetometer measurement is considered as the physically correct method which gives precise ferrite contents. It can magnetize and measure the total volume of sample and it can excite the specimen into magnetic saturation.

The AC magnetometer is a more practical method than the DC magnetometer but it has lower accuracy. From the measured maximum polarization value, the saturation polarization can be calculated only. The accuracy of the AC magnetometer can be improved using the so called multiphase hyperbolic model for the extrapolation. The extrapolated saturation polarization values are in good agreement with the results obtained by the DC magnetometer.

It was found the Feritscope showed lower ferrite contents than the DC magnetometer if it was used on plastic deformed samples. This difference was explained by the increases of coercivity due to plastic deformation. It is supposed the Feritscope derives the ferrite content from the initial permeability which decreases if the coercive field

\section{References}

[1] Jiles, D. C. "Review of magnetic methods for nondestructive evaluation", NDT International, 21(5), pp. 311-319, 1988.

https://doi.org/10.1016/0308-9126(88)90189-7

[2] Blitz, J. "Electrical and Magnetic Methods of Non-destructive Testing", Springer Science+Business Media, Dordrecht, Netherlands, 1997.

https://doi.org/10.1007/978-94-011-5818-3

[3] Devine, M. K. "The magnetic detection of material properties", JOM: The Journal of The Minerals, Metals \& Materials Society (TMS), 44(10), pp. 24-30, 1992. https://doi.org/10.1007/BF03223167

[4] Bozorth, R. M. "Ferromagnetism", Van Nostrand, New York, United States, 1951.

[5] Bödök, K. "Az ötvözetlen, gyengén és erősen ötvözött szerkezeti acélok korrózióállósága, különös tekintettel azok hegeszthetőségére" (Corrosion resistance of the non-alloyed, low-alloyed and high-alloyed structural steels, in particular for those weldability), Corweld, Budapest, Hungary, 1997. (in Hungarian)

[6] Dyja, D., Stradomski, Z., Kolan, C., Stradomski, G. "Eutectoid Decomposition of $\delta$-Ferrite in Ferritic-Austenitic Duplex Cast Steel - Structural and Morphological Study", Materials Science Forum, 706-709, pp. 2314-2319, 2012.

https://doi.org/10.4028/www.scientific.net/MSF.706-709.2314

[7] Nilsson, J.-O. "Super duplex stainless steels", Materials Science and Technology, 8(8), pp. 685-700, 1992.

https://doi.org/10.1179/mst.1992.8.8.685 increases. The Feritscope is a user friendly and portable device which is widespread in industry. It was found that the change of coercivity can strongly affect its accuracy. Therefore, the application of Feritscope device requires special attention in these cases.

The ferrite content results of the DC magnetometer, EBSD, first and second X-ray diffraction measurements were compared. Ferrite contents of the EBSD and second X-ray diffraction measurement are quite close to the results of the DC magnetometer but are slightly lower. The first X-ray diffraction measurement showed the highest ferrite content difference compared with the DC magnetometer and it furthermore determined extremely high $\sigma$-phase content too.

\section{Acknowledgement}

The research reported in this paper was supported by the Higher Education Excellence Program of the Ministry of Human Capacities in the frame of Nanotechnology research area of Budapest University of Technology and Economics (BME FIKP-NANO). The authors thank the Institute of Physical Metallurgy, Metalforming and Nanotechnology at the University of Miskolc for the X-ray diffraction measurements.

[8] Breda, M., Brunelli, K., Grazzi, F., Scherillo, A., Calliari, I. "Effects of Cold Rolling and Strain-Induced Martensite Formation in a SAF 2205 Duplex Stainless Steel", Metallurgical and Materials Transactions A, 46(2), pp. 577-586, 2015. https://doi.org/10.1007/s11661-014-2646-x

[9] Calliari, I., Bassani, P., Brunelli, K., Breda, M., Ramous, E. "Effect of Continuous Cooling on Secondary Phase Precipitation in the Super Duplex Stainless Steel ZERON-100", Journal of Materials Engineering and Performance, 22(12), pp. 3860-3866, 2013. https://doi.org/10.1007/s11665-013-0689-6

[10] Charles, J. "Duplex Stainless Steels - a Review after DSS '07 held in Grado", Materials Technology, 79(6), pp. 455-465, 2008. https://doi.org/10.1002/srin.200806153

[11] Varbai, B., Pickle, T., Májlinger, K. "Development and Comparison of Quantitative Phase Analysis for Duplex Stainless Steel Weld", Periodica Polytechnica Mechanical Engineering, 62(3), pp. 247-253, 2018. https://doi.org/10.3311/PPme.12234

[12] Vértesy, G., Mészáros, I., Tomáš, I. "Nondestructive indication of plastic deformation of cold-rolled stainless steel by magnetic minor hysteresis loops measurement", Journal of Magnetism and Magnetic Materials, 285(3), pp. 335-342, 2005. https://doi.org/10.1016/j.jmmm.2004.08.006

[13] Fiorillo, F. "Chapter 2-Soft Magnetic Materials", In: Characterization and Measurement of Magnetic Materials, Elsevier, Amsterdam, Netherlands, 2004, pp. 25-88. https://doi.org/10.1016/B978-012257251-7/50004-6 
[14] Stäblein, F., Steinitz, R. "Ein neuer Doppeljoch-Magnetstalprüfer" (A new double yoke magnetic tester), Archiv für das Eisenhüttenwesen, 8(12), pp. 549-554, 1935. (in German) https://oi.org/10.1002/srin.193500182

[15] Mészáros, I. "Testing of Stainless Steel by Double Yoke DC Magnetometer", Journal of Electrical Engineering, 61(7/s), pp. 62-65, 2010.

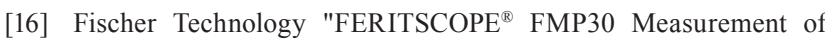
the Ferrite Content in Austenitic and Duplex Steel", [online] Available at: http://www.fischer-technology.com/fileadmin/documents/broc/EN/BROC_FMP30_FERITSCOPE_902-039_en.pdf [Accessed: 15 March 2020]

[17] Koblischka-Veneva, A., Koblischka, M. R., Mücklich, F. "Advanced microstructural analysis of ferrite materials by means of electron backscatter diffraction (EBSD)", Journal of Magnetism and Magnetic Materials, 322(9-12), pp. 1178-1181, 2010. https://doi.org/10.1016/j.jmmm.2009.06.073
[18] Max - Planck - Institut für Eisenforschung GmbH "Electron backscatter diffraction - EBSD", [online] Available at: https://www. mpie.de/3077954/EBSD [Accessed: 19 November 2019]

[19] Bunaciu, A. A., Udriştioiu, E. G., Aboul-Enein, H. Y. "X-Ray Diffraction: Instrumentation and Applications", Critical Reviews in Analytical Chemistry, 45(4), pp. 289-299, 2015. https://doi.org/10.1080/10408347.2014.949616

[20] Takacs, J., Mészáros, I. "Separation of magnetic phases in alloys", Physica B: Condensed Matter, 403(18), pp. 3137- 3140, 2008. https://doi.org/10.1016/j.physb.2008.03.023

[21] Mészáros, I. "Magnetic Measurement and Model Based Characterization of Phase Transformation in Lean Duplex Stainless Steel", Materials Science Forum, 721, pp. 96-101, 2012. https://doi.org/10.4028/www.scientific.net/MSF.721.96 